\title{
TERCEIRIZAÇÃO, ADOECIMENTO E ACIDENTES DE TRABALHO NA CONSTRUÇÃO CIVIL DA GRANDE VITÓRIA/ES ${ }^{1}$
}

\author{
OUTSOURCING, ILLNESS AND ACCIDENTS IN THE CONSTRUCTION \\ SECTOR IN GREATER VICTORIA/ES
}

Renata Silva Souza ${ }^{2}$

\begin{abstract}
RESUMO
Este artigo visa analisar a correlação entre a terceirização e a elevada acidentalidade no trabalho, causadora de mortes e mutilações no setor da construção civil da Grande Vitória, no Espírito Santo. Como procedimento metodológico, utilizou-se pesquisa documental com base na análise das edições do jornal Operário da Construção do SINTRACONST ${ }^{3}$ ES, na Convenção Coletiva de Trabalho da construção civil, assim como em relatórios do Ministério do Trabalho e Emprego, na RAIS ${ }^{4}$, nos estudos setoriais do DIEESE e nos anuários estatísticos do Ministério da Previdência Social. Além disso, realizou-se pesquisa empírica com aplicação de questionários estruturados a um recorte amostral de 190 trabalhadores terceirizados atuantes na construção civil na região metropolitana de Vitória/ES. Como resultado, constatou-se a existência de risco de morte por acidentes entre trabalhadores terceirizados da construção civil no subsetor de edificações na Grande Vitória/ES.
\end{abstract}

Palavras-chave: terceirização, acidentes, adoecimento, construção civil.

\begin{abstract}
This paper analyzes the correlation between outsourcing and high accident rates at work causing deaths and mutilations of outsourced workforce in the construction sector of Greater Vitória in state of Espírito Santo. As methodological procedure was used documentary research with analysis of editions of the journal Operário da Construção of SINTRACONST/ES and the Collective Labor Convention for civil construction. It was used also, reports of the Ministry of Labor and Employment and the RAIS, sectoral studies from DIEESE and statistical yearbooks of the Ministry of Social Security. In addition, was carried out empirical research with the application of structured questionnaires to a sample of 190 outsourced workers in the civil construction sector in Greater Vitória/ES. As a result, it was found that there is increased risk of death due to accidents between the outsourced workforce of the civil construction in the sub-sector of buildings in Greater Vitória/ES.
\end{abstract}

Keywords: outsourcing, accidents, illness, civil construction.

\footnotetext{
1 Este artigo é oriundo da Dissertação de Mestrado da autora intitulada "A Terceirização do trabalho no setor da construção civil na Grande Vitória/ES”, defendida em 2017 no Programa de Pós-Graduação em Política Social sob a orientação do Prof. Dr. Maurício de Souza Sabadini na Universidade Federal do Espírito Santo (UFES), com financiamento da Coordenação de Aperfeiçoamento de Pessoal de Nível Superior (CAPES). Obteve aprovação do Comitê de Ética em Pesquisa da UFES recebendo o registro de n. ${ }^{\circ}$ 1.534.336.

2 Doutoranda e Mestra em Política Social pela Universidade Federal do Espírito Santo (UFES). Bacharela em Serviço Social (UFES). Especialização pela University of California Irvine -Division of Continuing Education e Arizona State University. Pesquisadora do Núcleo de Estudos do Trabalho do Departamento de Serviço Social (UFES). Pesquisadora do Grupo de Pesquisa Estudos Marxistas sobre Teoria da Dependência da América Latina - Coletivo Anatália de Melo (UFES). Membro do Grupo de Estudos de América Latina do Centro de Política Comparada (CPC) (UFES).Email: renatas47@yahoo.com.br e renatascoser@gmail.com

3 SINTRACONST: Sindicato dos Trabalhadores da Construção Civil do Espírito Santo.

4 RAIS: Relação Anual de Informações Sociais.
} 


\section{INTRODUÇÃO}

O debate sobre a deterioração das condições de trabalho devido ao aumento da terceirização no Brasil avançou nos últimos anos, na medida em que esse processo assumiu proporções mais significativas nas empresas e nos serviços públicos. A situação de acirramento do debate entra em consonância com a necessidade premente dessa discussão, uma vez que a sociedade brasileira - por meio dos representantes legislativos e de grupos organizados da sociedade - tem dedicado esforços para regulamentar tal prática (DIEESE, 2013).

A terceirização não é nova. No caso brasileiro, conforme apontado por Paula Marcelino (2013), sua perspectiva foi adotada como exigência da globalização econômica, quando, no início de 1990, sob a política governamental do presidente Fernando Collor de Mello aprofundada no governo subsequente de Fernando Henrique Cardoso, tendo como base a justificativa de enfrentamento à crise econômica, foram estabelecidas medidas neoliberais, garantidoras de maior liberdade econômica, nas quais os direitos do trabalho foram taxados de riscos empresariais (MARCELINO, 2013). O resultado é que a ofensiva do capital exigiu a desregulamentação da mercadoria "força de trabalho".

A terceirização caracteriza-se como uma das medidas estratégicas de reestruturação do capital por meio do qual o capitalismo busca reduzir os "excessos" de gastos direcionados à força de trabalho, revelando a subproletarização da classe trabalhadora e, no oposto, a concentração de renda nas mãos do empresariado, cada vez mais internacionalizado e financeirizado (COUTINHO, 2015).

Desse modo, busca-se neste artigo discutir alguns elementos que interatuam na precarização do trabalho e afetam as condições laborais, com impactos na saúde dos trabalhadores terceirizados do setor da construção civil na Região da Grande Vitória/ES. A intenção deste estudo é ampliar a discussão sobre a terceirização na construção civil para além da perda de remuneração e benefícios, analisando principalmente o processo de precarização laboral com base na ocorrência de acidentes e no risco de mortes no ambiente de trabalho entre os trabalhadores terceirizados do segmento da construção, especificamente no subsetor de edificações. Para isso, utilizou-se como procedimento metodológico um estudo empírico com aplicação de questionários estruturados. Considerando-se o universo populacional de 4.000 trabalhadores, foi extraído um recorte amostral de 190 trabalhadores terceirizados atuantes na construção civil de edificações na região da Grande Vitória/ES. Cabe destacar ainda que o cálculo do recorte amostral deste estudo foi realizado por uma estatística profissional no Laboratório de Estatística do Centro de Ciências Exatas da Universidade Federal do Espírito Santo (UFES) por meio do programa estatístico Epidat.

Nesse contexto, com o objetivo de complementar os dados obtidos mediante aplicação dos questionários, foram realizadas, de forma aleatória, algumas entrevistas com representantes das entidades sindicais (laboral e patronal), assim como com alguns trabalhadores, na sede do Sindicato Laboral. A coleta dos dados empíricos foi realizada durante cinco meses no ano de 2016. Além disso, realizou-se ainda pesquisa documental por meio da análise das edições do jornal Operário da Construção, do SINTRACONST/ES, de estudos setoriais do DIEESE, dos anuários estatísticos do Ministério da Previdência Social e de relatórios estatísticos do Centro de Referência em Saúde do Trabalhador do Espírito Santo.

\section{TERCEIRIZAÇÃO NO BRASIL NA ATUALIDADE E SEUS REFLEXOS NA CONSTRUÇÃO CIVIL}

A sociedade contemporânea passa por profundas transformações que atingem a esfera da materialidade como resultado da crise experimentada pelo capital e das respostas elaboradas pelas classes dominantes para administrá-la. 
A nova e profunda crise do capitalismo global, cujo núcleo central é a crise financeira de 2008, expôs a instabilidade estrutural do sistema mundial do capital. Desse modo, o acirramento da precarização do trabalho nas primeiras décadas do século XXI não significa mera falha contingente da regulação social e política do trabalho, mas sim da necessidade de desvalorização da força de trabalho no sistema mundial produtor de mercadoria em sua etapa de crise estrutural de valorização (ALVES, 2013; MÉSZÁROS, 2011).

Nesse contexto, a terceirização como técnica por demais sofisticada de precariedade laboral extrema, levada a cabo no presente momento, pretende retirar do conflito entre capital e trabalho os verdadeiros capitalistas dessa relação eminentemente conflituosa. Por meio dela se dá a substituição - por pequenos agentes econômicos - dos grandes capitalistas os quais obtêm a fração mais expressiva de lucros com a exploração de determinada força de trabalho (COUTINHO, 2015).

Conforme Coutinho (2015), a inserção da terceirização nas relações de trabalho na ordem mundial ocorreu do ponto de vista da dinâmica produtiva, com base na acumulação flexível, que por sua vez é pressuposto inarredável do capitalismo global. O Brasil aderiu a essa "forma nova de ser" do capitalismo histórico mais enfaticamente a partir dos anos 1990, com a adoção de políticas diversas de precarização e desregulamentação do Direito do Trabalho sob o receituário de governos neoliberais no país.

Ao discorrer sobre as relações precárias de trabalho, torna-se importante definir que na literatura o significado conceitual para o termo precário diz respeito a uma mudança, para pior, na qualidade não somente das relações de emprego, mas das condições de trabalho, acirrada no capitalismo com a passagem da forma de produção fordista para a produção flexível (DRUCK, 2011).

Na última década, a terceirização vem se convertendo em instrumento central das estratégias de gestão corporativa. A importância desse mecanismo de contratação, entre outros aspectos, deve-se ao fato de, ao dissimular as relações sociais estabelecidas entre capital e trabalho, elas são convertidas em relações inter-empresas (ANTUNES; DRUCK, 2014; DRUCK, 2011).

A explosão de empresas terceirizadas tem sido um importante propulsor de empresas geradoras de mais-valia que, no passado recente, eram estatais prestadoras de serviços sem fins lucrativos. Com a privatização, elas se tornaram partícipes diretas ou indiretas do processo de valorização do capital, incrementando e ampliando as modalidades de extração direta ou indireta de mais-valia (DRUCK, 2011).

Dessa forma, a terceirização apresenta-se como um dos determinantes no processo de transformação no mercado de trabalho e tem origem na palavra terceiro, entendido como intermediário ou interveniente (CHERCHIGLIA, 2004). Na linguagem empresarial, caracterizase como uma técnica de administração por meio da qual se interpõe um terceiro, geralmente uma empresa, que assumirá o serviço ou a atividade terceirizada (CHERCHIGLIA, 2004). A terceirização consiste em transferir a terceiros a execução de tarefas para as quais a relação custo/benefício da execução interna não é das mais vantajosas, seja do ponto de vista financeiro, seja de especialidade.

Paula Marcelino elabora uma definição da terceirização não meramente técnica, mas que contempla sua dimensão política. Segundo a autora, "a terceirização é todo processo de contratação de trabalhadores por empresa interposta, cujo objetivo é a redução de custos com a força de trabalho e a externalização dos conflitos trabalhistas" (MARCELINO, 2013, p. 50). Nesse contrato, privilegia-se a relação empregatícia porque, segundo Marcelino (2013) é na 
natureza dos contratos estabelecidos entre as empresas e os trabalhadores com a intermediação da força de trabalho que os lucros são auferidos. O reconhecimento da importância política da terceirização demonstra que sua utilização não visa somente à redução de custos, ampliando a exploração da força de trabalho, mas também atingir a organização da classe trabalhadora, recompondo o domínio exercido sobre esta e suas organizações (MARCELINO, 2013).

No Brasil, o processo de terceirização encontrou espaço considerável para sua inserção. Contando com o apoio da frágil legislação trabalhista brasileira, a terceirização adentrou as áreas industriais, passando nas décadas de 1980 e 1990 a se expandir para outras áreas do mundo do trabalho brasileiro, principalmente no setor da construção civil de edificações (AZEVEDO, 2014; CUNHA, 2015).

Desse modo, a construção civil, especificamente o subsetor de edificações, não escapou dessa conjuntura, e vários esforços têm sido feitos por suas empresas para atingirem níveis mais altos de qualidade e produtividade, conforme um processo de atualização e revisão das práticas tradicionais. Como uma das principais estratégias de competitividade adotadas pelas empresas da construção, o subsetor edificações tem verificado um progressivo emprego da terceirização nas etapas construtivas (CUNHA, 2015).

Nessa perspectiva, os impactos da terceirização na construção civil brasileira são evidentes, visto que nesse setor o processo de terceirização tem assegurado maior flexibilidade às empresas, ao mesmo tempo em que tende a precarizar o trabalho ao se tornar um mero artifício para driblar encargos sociais e trabalhistas e de radicalizar a individualização, no sentido de que distancia ainda mais a empresa da responsabilidade pelos trabalhadores que produzem seus lucros (FILGUEIRAS, 2015). Somado a isso, conforme este autor, o crescimento nos índices de adoecimentos e acidentes de trabalho na construção civil mostra-se como uma das conseqüências da terceirização nesse setor econômico, demonstrando que o referido fenômeno tem contribuído para o avanço da precarização das relações e condições laborais entre a força de trabalho operária da construção (FILGUEIRAS, 2015).

Desse modo se evidenciam, por meio das mais distintas modalidades da terceirização, novas condições de trabalho que definem trabalhadores de "primeira" e "segunda" categorias, revelando assim a distinção ou condição de inferioridade e desigualdade. No setor da construção civil de edificações, as diferenças acentuam-se igualmente para a força de trabalho terceirizada nas jornadas mais prolongadas, no ritmo e na intensidade do trabalho, nos níveis mais altos de rotatividade, nos salários reduzidos, nas condições de insegurança e insalubridade, entre tantos outros fatores.

Nessa lógica, as condições de trabalho no âmbito da terceirização - e a partir desta -, o índice de acidentes ocorridos e de doenças adquiridas no ambiente laboral compõem o tecido conjuntivo das relações sociais de trabalho no segmento da construção civil, pondo ainda em evidência a condição de exploração e as contradições reais existentes entre a classe trabalhadora.Assim, a terceirização aumenta ainda mais a fragmentação, a heterogeneização e a divisão intraclasse trabalhadora, ampliando a concorrência entre os que trabalham no mesmo espaço produtivo (COUTINHO, 2015).

Dessa forma, a terceirização promove a pulverização dos sindicatos, fazendo com que, não raro, na mesma empresa os trabalhadores dos diferentes setores terceirizados tenham representação sindical diferenciada, fragmentando ainda mais suas possibilidades de organização, união, solidariedade e resistência de classe e, no caso específico da construção civil, aprofundando ainda mais a vulnerabilidade das condições laborais entre sua força de trabalho terceirizada. 


\section{VULNERABILIDADE DAS CONDIÇÕES DE TRABALHO NA CONSTRUÇÃO DE EDIFICAÇÕES DA GRANDE VITÓRIA/ES}

Quando se fala em precarização das condições de trabalho, serviços exaustivos, jornadas excessivas, acidentes e adoecimentos laborais recorrentes, inegavelmente associam-se as mazelas e os males decorrentes do trabalho humano degradante ao enorme desgaste sofrido pela classe trabalhadora ao longo de sua trajetória na sociedade capitalista (ALVES, 2013).

Em que pese às condições de trabalho, torna-se oportuna a definição de tal termo, que por sua vez está relacionado às questões existentes no ambiente físico e organizacional onde as atividades de trabalho são realizadas, como segurança, saúde e alimentação. Todos esses elementos, quando presentes inadequadamente no local de trabalho, podem provocar problemas e sofrimento à vida do operário, a exemplo de doenças profissionais e do trabalho, bem como de doenças psíquicas (RODRIGUES; ALVARO; RONDINA, 2006).

De acordo com o relatório do Ministério da Previdência Social (BRASIL, 2006), doenças profissionais são produzidas ou desencadeadas pelo exercício do trabalho peculiar a determinado ramo de atividade, enquanto doenças do trabalho são aquelas adquiridas ou desencadeadas em função de condições especiais em que a atividade profissional é realizada e com as quais se relacionam diretamente.

À luz dessas contextualizações, percebe-se que uma das faces do perverso novo mundo laboral e da autocracia ainda marcante na relação entre o capital e o trabalho se evidencia no exacerbado número de doenças físicas e emocionais adquiridas em função do desempenho de determinadas atividades, considerando, sobretudo, o poder despótico exercido pelos proprietários dos meios de produção (FILGUEIRAS, 2015). Sendo assim, tendo como base os dados coletados para este estudo, é possível identificar que as sequelas laborais passam a integrar, com a mesma intensidade, a rotina dos operários terceirizados no setor da construção de edifícios na Grande Vitória/ES.

Nessa perspectiva, observa-se que faltam - por parte da maioria das empreiteiras terceirizadas da construção civil capixaba - preocupação e investimentos na qualidade do ambiente de trabalho. O excesso de exposição à poeira, a posições incômodas, ao peso excessivo, bem como ao barulho exacerbado nas obras causado pela particularidade do processo de trabalho realizado no segmento da construção, tem propiciado um grande desconforto aos trabalhadores do setor, como evidenciado na Tabela 1, referente aos fatores físicos e químicos que afetam a saúde da força de trabalho terceirizada da construção civil de edificações.

\section{TABELA 1 - FATORES FÍSICOS E QUÍMICOS PREJUDICIAIS À SAÚDE DA FORÇA DE TRABALHO TERCEIRIZADA, CONST. CIVIL GRANDE VITÓRIA/ES 5 - 2016}

\begin{tabular}{lcc}
\hline Fatores de risco à saúde no ambiente laboral & Frequência & Porcentagem $\mathbf{\%}(\mathbf{n = 1 9 0})$ \\
\hline Peso excessivo & 109 & 57,4 \\
\hline Poeira & 64 & 33,7 \\
\hline
\end{tabular}

\footnotetext{
Com relação à análise dos dados obtidos na pesquisa de campo, efetuou-se a sistematização deles por meio da elaboração de tabelas com a utilização do Programa Estatístico SPSS. As variáveis foram analisadas por métodos da estatística descritiva, como frequências e percentuais. A associação entre variáveis foi verificada pelo teste qui-quadrado ou exato de Fisher (quando os valores esperados foram menores do que 5), considerando um nível de significância de 5\%. Além disso, cabe salientar que o tratamento e a sistematização dos dados empíricos deste estudo foram realizados pelo Núcleo de Estatística do Centro de Pesquisa da Escola Superior de Ciências da Santa Casa de Misericórdia de Vitória/ES, com a supervisão de um estatístico profissional.
} 


\begin{tabular}{lcc}
\hline Fatores de risco à saúde no ambiente laboral & Frequência & Porcentagem $\mathbf{\%}(\mathbf{n}=\mathbf{1 9 0})^{*}$ \\
\hline Ruído & 46 & 24,2 \\
\hline Posições incômodas & 42 & 22,1 \\
\hline Calor & 7 & 3,7 \\
\hline Gases & 5 & 2,6 \\
\hline Vapores & 5 & 2,6 \\
\hline
\end{tabular}

Fonte: Questionários aplicados junto aos trabalhadores da Construção Civil na Grande Vitória/ES em 2016.

* \% $(\mathrm{n}=190)$ significa que o percentual exposto relativo a cada variável representa a \% do total da amostra de 190, visto que a questão contida no questionário referente aos fatores de risco à saúde no ambiente de trabalho requeria dos trabalhadores pesquisados possíveis múltiplas respostas (Núcleo de Estatística).

Os dados expostos na tabela anterior estão relacionados às variáveis concernentes aos fatores de risco à saúde no ambiente laboral mais vivenciados pelos trabalhadores nos canteiros de obras da construção. Assim, como pode ser observado na tabela anterior, $57 \%$ da força de trabalho terceirizada da construção relatam que sofrem com o peso excessivo em sua rotina laboral. Verifica-se na mesma tabela que a frequência de operários afetados pela exposição à poeira é de $33 \%$, seguindo-se de $24 \%$ de trabalhadores que sofrem com o ruído excessivo nas obras e $22 \%$ com problemas relacionados a posições incômodas durante o desempenho das atividades. Fatores associados a calor, gases e vapores correspondem, respectivamente, a3,7\%, e $2,6 \%$ de declarações dos operários pesquisados.

No percurso deste estudo, os trabalhadores terceirizados na construção ainda apontaram os seguintes problemas de saúde adquiridos ao longo de anos de atividade no setor: lesões na coluna, dor lombar (lombalgia), reumatismos e artroses (em pernas e joelhos), lesões por esforço repetitivo (em mãos e braços), dores de cabeça (cefaleia), doenças respiratórias e problemas de surdez.

Nesse contexto, um aspecto importante suscitado no depoimento de um dos trabalhadores corrobora os dados explicitados na tabela supramencionada, quando se refere ao desgaste físico causado pelo trabalho em tarefas tidas como pesadas:

O trabalho aqui é muito cansativo para nós, eu chego em casa morto de cansado porque eu pego muito peso aqui no canteiro. Já estou com problemas de coluna por causa disso, já até usei atestado médico para poder me consultar no ortopedista. Sou pedreiro e carrego muito saco de cimento pesado nas costas... o excesso de peso é uma realidade na minha função e infelizmente eu tenho que conviver com isso, porque é a única coisa que sei fazer na vida (Trabalhador G., 34 anos, canteiro de obra na Serra).

Outro operário, por sua vez, aponta como prejudicial a sua saúde o excesso de barulho, ou seja, o ruído excessivo no canteiro de obras: "Tenho dificuldade em ouvir bem, o alto grau de ruído das máquinas utilizadas na obra tem prejudicado minha audição" (Trabalhador J., 49 anos, Sede do SINTRACONST-ES).

Serviços que exigem manipulação de equipamentos pesados e de materiais, como cimentos e areia, além da exposição frequente às intempéries de clima, contribuem para o adoecimento físico dos trabalhadores do setor. As tarefas de servente de pedreiro são as mais duras e insalubres do canteiro de obras: serviços de limpeza, de carregar e descarregar os caminhões, preparo de massa, transportar entulho etc (SANTOS FILHO, 2011; DAL ROSSO, 2008). 
Tal realidade constitui um quadro indicativo da preponderância do trabalho manual, em que o trabalhador está continuamente exposto não somente ao perigo de acidentes de trabalho, mas igualmente a outras lesões e doenças profissionais (DAL ROSSO, 2008).

A essa situação se acresce o fato de que $63 \%$ dos trabalhadores terceirizados pesquisados já fizeram uso de atestado médico. Nesse aspecto, faz-se conveniente ressaltar que o contexto de adoecimento vivenciado pelos trabalhadores terceirizados da construção civil capixaba torna-se ainda mais preocupante quando os dados coletados para este estudo revelam que $71 \%$ deles não têm plano de saúde. Isso significa que as empreiteiras terceirizadas da construção civil de edificações circunscritas na Grande Vitória/ES não fornecem a assistência médica necessária para o bem-estar do trabalhador, contribuindo dessa forma para o agravamento da precarização das condições de trabalho e, consequentemente, da saúde da força de trabalho terceirizada do setor (SOUZA, 2017).

Tais apontamentos são fundamentados na análise feita por Filgueiras (2015) em seu estudo sobre Saúde e Segurança do Trabalho na Construção Civil, que aponta o padrão de gestão da saúde e segurança do trabalho na construção civil no Brasil como caracterizado pela tendência a negar a existência do adoecimento laboral no setor. A grande subnotificação de doenças ocupacionais é uma estratégia deliberada de condução dos negócios e tem-se intensificado instrumentalmente nos últimos anos (FILGUEIRAS, 2015).

No que diz respeito à vivência de sofrimento no trabalho, torna-se visível a situação crítica das condições laborais engendradas entre a força de trabalho terceirizada da construção civil na Grande Vitória/ES em todos os fatores a ela pertinentes, conforme já expressado anteriormente nas falas de alguns dos trabalhadores pesquisados. Somado a isso, há ainda outros agravos comuns aos trabalhadores da construção civil, como o alcoolismo, doenças mentais e doenças psicossomáticas, que podem ser tomados como sintomas do sofrimento provocado pelo trabalho e que geram por consequência o enfraquecimento da organização coletiva de classe (FILGUEIRAS, 2015; DEJOURS, 2011).

Dejours (2011), ao se referir às consequências subjetivas da precarização, destaca o medo constante do trabalhador em relação à empresa em virtude das demissões impostas por esta, bem como a intensificação do trabalho como mecanismo de aumento do sofrimento subjetivo e a neutralização das mobilizações contra a dominação e a alienação. Nessa perspectiva, Dejours (2011) ainda salienta, no contexto do sistema sociometabólico do capital, o que chamaria de o mal nas práticas ordinárias do trabalho, que nas palavras do autor se caracteriza pela

[...] participação em se tratando da injustiça e do sofrimento infligidos a outrem. Trata-se ainda, sobretudo, de infrações cada vez mais frequentes e cínicas das leis trabalhistas: empregar pessoas sem carteira de trabalho para não pagar as contribuições da Previdência Social e poder demiti-las em caso de acidente de trabalho, sem penalidade como acontece na construção civil[...] (2011, p. 76).

Ainda conforme esse autor, o trabalho pode ser mediador de emancipação, entretanto, contraditoriamente para os que têm um emprego, também continua a gerar sofrimentos. Nessa direção, os trabalhadores que sofrem por causa do aumento da carga de trabalho e da fadiga, ou ainda por causa da degradação progressiva das relações de trabalho (direitos trabalhistas não respeitados, arbitrariedade das decisões, individualismo, concorrência desleal entre agentes, arrivismo desenfreado etc.), podem sofrer com o adoecimento psíquico e "encontram muitas dificuldades para reagir coletivamente" (DEJOURS, 2011, p. 43). 
Isso posto, convém aqui ressaltar a importância das contribuições de Christophe Dejours (2003) nos estudos da Psicodinâmica do Trabalho ${ }^{6}$ acerca da análise da relação entre saúde mental e trabalho, que por sua vez tem como objetivo a compreensão do sofrimento produzido no trabalho e o gerenciamento deste, bem como o estudo das ferramentas utilizadas pelo trabalhador na busca de prazer, a fim de manter o equilíbrio psíquico dessa força de trabalho em situações patológicas no ambiente laboral. Além disso, privilegia os impactos da organização do trabalho ${ }^{7}$ (hierarquia, controle, ritmo, estilo gerencial, relações humanas) sobre a saúde mental do trabalhador, considerando que as condições de trabalho (condições físicas, químicas e biológicas do ambiente de trabalho) se refletem consideravelmente sobre a saúde física e principalmente psíquica do trabalhador (DEJOURS, 1992). Isso porque as condições laborais, as pressões e imposições advindas da organização do trabalho engendradas na realidade laborativa em que está inserido o trabalhador ignora a subjetividade desse sujeito. Em vista disso, verifica-se uma barreira na relação do trabalhador com a organização do trabalho, causando uma carga psíquica do trabalho sobre o indivíduo (DEJOURS, 2003, 2004).

Nesse contexto, à luz dessas considerações, o que se constata é que a sociabilidade capitalista é a sociedade do trabalho estranhado e subsumido às imposições do capital, isso porque a organização das atividades incorpora o caráter do trabalho alienado, o que desencadeia a fragmentação e a dessubjetivação de classe entre os trabalhadores (ALVES, 2013).

É no referido contexto de alienação e estranhamento que se insere a força de trabalho da construção civil capixaba, uma vez que nela ocorre a negação humana dos trabalhadores que laboram nesse setor, ou seja, esses sujeitos são relegados à mera condição de mercadoria degradada, visto que são deslocados pelo recurso à terceirização e ao trabalho precário. $\mathrm{O}$ exército industrial de reserva (MARX, 1996), então, cumpre a função de colocar os trabalhadores empregados na construção de edificações capixaba numa situação de submissão a determinadas condições de trabalho para garantir seu sustento.

A análise da relação terceirização-trabalho-saúde conforme encontrada no estudo realizado sugere que os problemas de saúde entre a força de trabalho terceirizada da construção aumentam de forma gigantesca. Aponta ainda que, ao lado dos problemas típicos da sociedade industrial, ocorre ainda o aumento na incidência de acidentes no ambiente de trabalho no setor da construção civil.

\section{ACIDENTES DE TRABALHO COMO CONSEQUENCIA PERVERSA DA TERCEIRIZAÇÃO DA FORÇA DE TRABALHO NA CONSTRUÇÃO CIVIL DE EDIFICAÇÃO CAPIXABA}

\footnotetext{
${ }^{6} \mathrm{O}$ debate sobre a psicodinâmica do trabalho foi apresentado por Christophe Dejours por meio da publicação de A loucura do trabalho: estudo de psicopatologia do trabalho. Esta obra traz uma nova compreensão das relações entre trabalho e saúde do trabalhador, sendo uma importante referência na área da saúde mental no trabalho. A psicodinâmica do trabalho destaca-se por privilegiar a clínica como modo de análise do trabalho, como instrumento capaz de compreender tanto os processos de saúde quanto as patologias do trabalho. Nessa perspectiva, saúde no trabalho significa o potencial de cada trabalhador em utilizar os recursos internos e externos para transformar o sofrimento causado no trabalho em busca por prazer e realização. Desse modo, a psicodinâmica do trabalho analisa a forma como o trabalhador se utiliza dessas estratégias defensivas para se manter saudável em meio a uma organização do trabalho patologizante. Ler Dejours (2004).

7 A categoria "organização do trabalho" compreende a divisão do trabalho, as relações laborais, o sistema hierárquico e as relações de poder no conjunto de atividades desenvolvidas pelos trabalhadores (DEJOURS, 2003; 2004). Torna-se oportuno salientar que, não obstante a importância da categoria "organização do trabalho" nos estudos da psicodinâmica laboral, optou-se por preterir a análise dessa categoria neste estudo, pois tal debate não é o objetivo central deste artigo, que visa analisar a correlação entre a terceirização e a elevada acidentalidade no trabalho no setor da construção civil.
} 
Ao lado da importância real que representa para a economia nacional e regional, por ser um dos principais setores responsáveis pela absorção da força de trabalho das camadas mais pobres da população, devido à pouca exigência para a contratação em termos de qualificação, o ramo da construção civil abriga uma dura realidade, de modo que tal setor é considerado um dos mais perigosos em todo o mundo, tendo em vista que lidera as taxas de acidentes de trabalho fatais e não fatais, em particular os acidentes típicos (SILVA, 2013).

Filgueiras (2015) aponta a construção civil como um dos ramos da atividade econômica com maior ocorrência de acidentes de trabalho. Conforme esse autor, com base no Anuário Estatístico de Acidentes de Trabalho (AEAT) do Instituto Nacional de Seguridade Social (INSS) e do Ministério da Previdência Social (BRASIL, 2013), de todos os acidentes registrados anualmente pelo INSS, 3 (três) mil se referem à morte de trabalhadores no setor da construção civil, de modo que a participação desse setor no total de acidentes fatais registrados no Brasil passou de 10,1\%, em 2006, para 16,5\%, em 2013 (FILGUEIRAS, 2015; BRASIL, 2013).

No subsetor construção de edifícios, a taxa de mortalidade é o dobro do conjunto do mercado de trabalho. Por contar com maioria de trabalhadores terceirizados no Espírito Santo, esse subsetor teve mais terceirizados mortos, conforme o estudo de Filgueiras (2015). Desse modo,foram 135 trabalhadores mortos em 2013, sendo 75 terceirizados (55,5\% dos mortos) e 60 contratados diretos, considerando o Espírito Santo (FILGUEIRAS, 2015).

Segundo o relatório do Ministério da Previdência Social (BRASIL, 2006), define-se como acidente de trabalho aquele que ocorre pelo exercício da atividade profissional a serviço da empresa ou pelo exercício do trabalho dos segurados especiais, provocando lesão corporal ou perturbação funcional, permanente ou temporária, que cause a morte, a perda ou a redução da capacidade para o trabalho.

À luz dessas considerações, a precarização do trabalho engendrada pela terceirização tem contribuído igualmente para o incremento dos acidentes e das mortes na construção civil no Espírito Santo e na Grande Vitória. Tal fato pode ser corroborado pelos dados do Centro de Referência de Saúde do Trabalhador do Espírito Santo (CEREST-ES), devidamente sistematizados no seguinte gráfico:

\section{GRÁFICO 1 - ÍNDICE DE ACIDENTES TÍPICOS E DE TRAJETO NA CONSTRUÇÃO CIVIL - ESPÍRITO SANTO E GRANDE VITÓRIA/ES - 2013-2016}

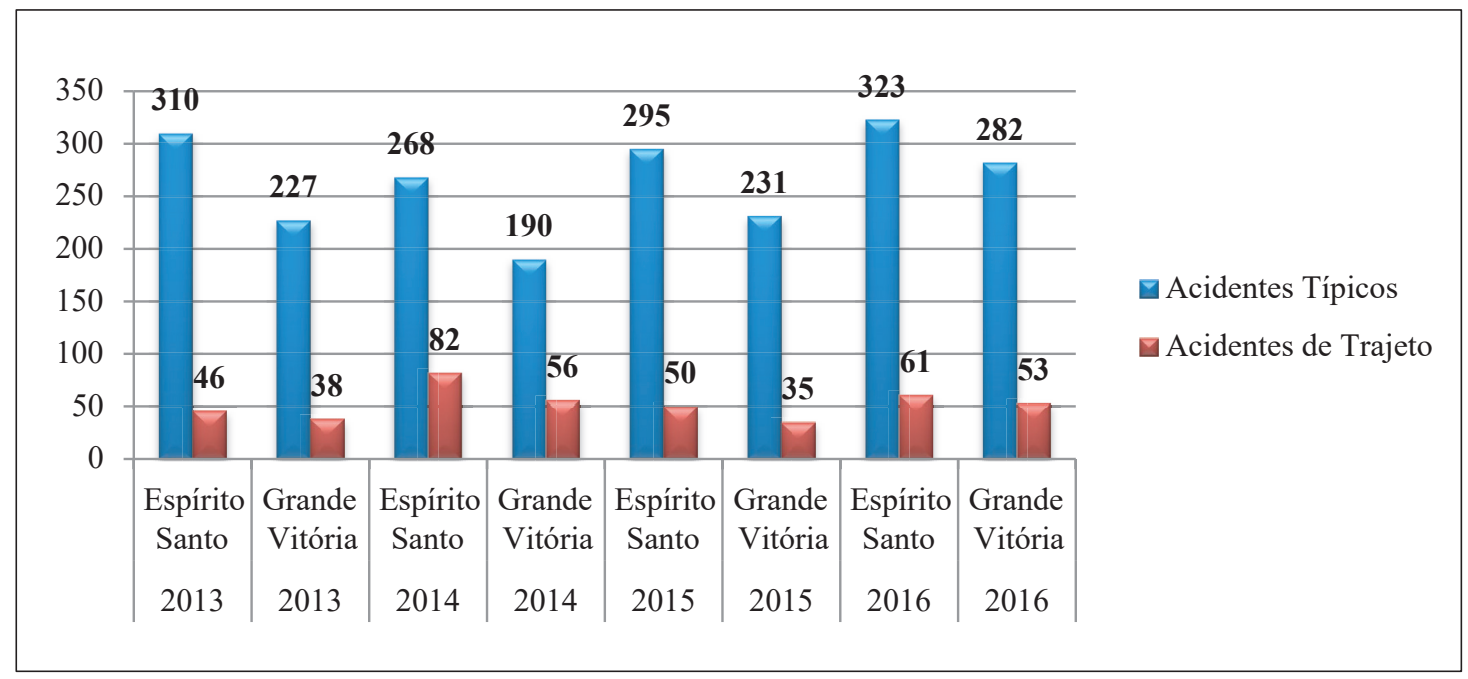

Fonte: Centro de Referência de Saúde do Trabalhador-Espírito Santo (CEREST-ES),Comunicação de Acidentes de Trabalho (CATs). 
Nessa perspectiva, torna-se pertinente a explicitação acerca dos acidentes típicos de trabalho, que por sua vez são decorrentes da característica da atividade profissional desempenhada pelo acidentado. Desse modo, acidentes de trajeto são aqueles ocorridos no trajeto entre a residência e o local de trabalho do segurado e vice-versa, conforme o Ministério da Previdência social (BRASIL, 2006).

No Gráfico $1^{8}$ é possível verificar, ao longo da série histórica entre 2013 e 2016, o alto índice de acidentes de trabalho típicos em relação àqueles considerados de trajeto tanto em nível estadual, considerando o Espírito Santo em sua totalidade, como em nível regional, quando é observada a Região Metropolitana da Grande Vitória. Em 2013, o CEREST-ES registrou no Espírito Santo (ES) 310 acidentes laborais típicos e 46 de trajeto, sendo que na Grande Vitória o índice ficou em 227 acidentes típicos e 38 de trajeto. Porém, no ano de 2014 nota-se uma queda no índice de acidentes típicos no ES e igualmente na Grande Vitória, em relação ao ano anterior de 2013, com 268 e 190, respectivamente. Todavia, no mesmo ano de 2014 há um ligeiro aumento dos acidentes de trajeto se comparado ao ano de 2013, evidenciado por 82 acidentes no ES e 56 na Grande Vitória. Por outro lado, em 2016 identifica-se o aumento desses acidentes de trabalho de modo que entre aqueles qualificados como típicos observa-se a quantidade de 323 no ES, o que representa um incremento de +28 acidentes no estado em relação ao ano anterior de 2015 , enquanto que na Grande Vitória nota-se uma taxa de 282 acidentes típicos, evidenciando o acréscimo de + 51 acidentes quando comparado ao mesmo ano de 2015.

No entanto, vale ressaltar que os dados expostos no Gráfico 1 se referem apenas aos acidentes de trabalho comunicados, e que tais dados foram extraídos da base estatística do CEREST do Espírito Santo. Segundo apontado pelo relatório do CEREST-ES (2016), um número imenso de acidentes é omitido, ou seja, para grande parte dos acidentes ocorridos não há emissão de Comunicação de Acidentes de Trabalho (CAT) por parte das empresas da construção para o Instituto Nacional de Seguridade Social (INSS), conforme mencionado pelo relatório do CEREST-ES (2016).

Quando se considera a força de trabalho terceirizada, verifica-se igualmente que a omissão da notificação dos acidentes parece atingir mais os trabalhadores terceirizados do setor. De acordo com o estudo de Filgueiras feito com base nos dados do Ministério Público do Trabalho, dos acidentes fatais ocorridos em 2013 - considerando somente o Espírito Santo -, para os quais foram lavrados autos de infração pela Fiscalização do Trabalho (até 24/06/2014) por falta de comunicação ao MTE, 23 acidentes não comunicados eram referentes a trabalhadores terceirizados e quatro eram relativos a contratados diretos.

Esse agravamento na intensificação de acidentes laborais na construção civil de edificações é confirmado - agora somente para a Grande Vitória/ES - pelos dados obtidos na pesquisa de campo para este estudo e sistematizados na Tabela 2.

\footnotetext{
${ }^{8}$ Para esclarecimento: optou-se por preterir as doenças profissionais (alcoolismo e transtornos mentais e comportamentais, descritos como problemas de saúde mental) do referido gráfico e da análise desta seção, uma vez que tal debate não é o objetivo central deste artigo, cujo foco principal é analisar a correlação entre a terceirização e a elevada acidentalidade no trabalho no setor da construção civil.
} 


\section{TABELA 2 - ACIDENTES TÍPICOS E DE TRAJETOS FORÇA DE TRABALHO TERCEIRIZADA NA CONSTRUÇÃO CIVIL DA GRANDE VITÓRIA/ES - 2016}

\begin{tabular}{lccc}
\hline \multicolumn{1}{c}{ Condições de trabalho } & & Frequência & Porcentagem $\%$ \\
\hline Ocorrência acidentes de trabalho & $\operatorname{Sim}$ & 112 & 58,9 \\
\hline & Não & 78 & 41,1 \\
\hline Tipos de acidentes de trabalho & Total & $\mathbf{n = 1 9 0}$ & $\mathbf{1 0 0 , 0}$ \\
\hline & Acidente típico & 107 & \\
\hline & Acidente de trajeto & 5 & 96,0 \\
\hline & Total & $\mathbf{n = 1 1 2}$ & $\mathbf{1 0 0 , 0}$ \\
\hline
\end{tabular}

Fonte: Questionários aplicados junto aos trabalhadores da construção civil da Grande Vitória/ES.

Conforme demonstrado na Tabela 2, verifica-se a existência considerável de acidentes de trabalho entre os trabalhadores terceirizados na construção de edificações na Grande Vitória. Dos 190 operários pesquisados, 112, isto é, aproximadamente $58 \%$, afirmam já ter sofrido algum tipo de acidente no ambiente de trabalho. Dentre esses 112 acidentes, 107 desses, em torno de $96 \%$, configuram acidentes típicos e apenas 4,0\% são caracterizados como de trajeto.

Os dados mencionados na Tabela 2 corroboram o argumento de Dal Rosso (2008), para quem os acidentes típicos registrados envolvem em maiores números as quedas de alturas principalmente de andaimes de balanço e elevadores suspensos, que em muitos casos provocam, de acordo com informações da Secretaria de Saúde do SINTRACONST/ES, fraturas nas pernas, na cabeça e na coluna vertebral -, seguidas de choques elétricos, problemas nos pés, ferimentos nos dedos, mãos e braços por meio de manuseio de máquinas ou ferramentas cortantes. Assim, os acidentes típicos mais identificados neste estudo empírico foram as quedas (66\%), grande parte associadas a andaimes, plataformas, telhados, edifícios ou estruturas (SOUZA, 2017).

Nessa perspectiva, o sociólogo do trabalho Sadi Dal Rosso (2008) argumenta que os problemas de maior gravidade decorrentes de acidentes na construção civil são em geral as lesões físicas, que requerem longos ou médios tratamentos, e aqueles acidentes que conduzem a afastamento permanente do trabalhador de sua ocupação ou o levam à morte.

Todavia, cabe aqui reiterar que tais acidentes de trabalho, especialmente os caracterizados como típicos, segundo apontamentos do CEREST-ES, ocorrem devido ao fornecimento de Equipamentos de Proteção Individuais (EPI's) e Coletivos (EPC's) de baixa qualidade por muitas empreiteiras terceirizadas ou são decorrentes do não fornecimento de tais equipamentos de segurança aos trabalhadores por parte das terceirizadas, conforme expressam as denúncias publicadas no jornal Operário da Construção: "A gata", a empreiteira Arte Nova, está obrigando seus operários a trabalharem sem Equipamentos de Proteção Individual" (SEÇÃO PAU NA GATA, 2014), e ainda

Em uma obra da gata (terceirizada) no município de Guarapari, bebedouro e estufa ficam expostos ao tempo, sem qualquer preocupação com higiene ou qualidade de vida para os trabalhadores. Falta até EPI para todos os trabalhadores, o que coloca em risco sua integridade e ainda desobedece a NR 18. Trabalhadores expostos a perigo e ao

\footnotetext{
9 O termo gata se refere às inúmeras empresas/empreiteiras terceirizadas existentes no setor da construção que tentam burlar a legislação trabalhista, prejudicando os trabalhadores desse segmento.
} 
risco de doenças por negligência patronal. Trabalhador nas alturas sem cinto, nem EPI, sem guarda corpo ou qualquer forma de proteção. (SEÇÃO PAU NA GATA, 2016).

O discurso contido nesses artigos jornalísticos revela a essência da realidade vivenciada pelos trabalhadores terceirizados nesse segmento, demonstrando que as condições de segurança do trabalho na construção civil capixaba são muito precárias. Os acidentes ocorridos nessa área normalmente são previsíveis e estão relacionados ao descumprimento expresso da NR 18, que regulamenta a Segurança e Medicina do Trabalho na Indústria da Construção Civil. O descumprimento de regras para instalações de andaimes e proteções periféricas é o que mais se destaca. Essa observação explica a permanência das quedas de altura como causa principal dos acidentes fatais, conforme apontado por Filgueiras (2015).

Nessa lógica, o trabalhador terceirizado se torna mais fragilizado frente à empresa que lucra com seu labor (FILGUEIRAS, 2015). Ou seja, para o tomador, externalizar os riscos significa aumentar seu poder de gerir a força de trabalho sem preservar sua integridade física, de modo que a terceirização é um escudo para as empresas tomadoras de serviços. Ao nominar outra pessoa, física ou jurídica, como responsável pelos trabalhadores, a contratante quase sempre se exime, na prática, da adoção de medidas para preservar a integridade física deles.

Ademais, a externalização dos riscos, promovida pela terceirização, acentua dramaticamente uma das principais características da forma de regulação privada hegemônica nas empresas brasileiras: a individualização da segurança e saúde do trabalho. O cerne dessa dinâmica é bem ilustrado pelas quase uníssonas afirmações dos representantes do Sindicato da Indústria da Construção Civil/ES (SINDUSCON/ES) após os acidentes : "a empresa forneceu o equipamento de proteção individual, a culpa é do trabalhador que morreu" (Depoimento de N., representante do SINDUSCON/ES, 2016). Nesse sentido, a terceirização radicaliza a individualização, pois tende a distanciar ainda mais a empresa da responsabilidade por preservar a integridade física daqueles que produzem seus lucros (DRUCK; FRANCO, 2007; COUTINHO, 2015).

O discurso contido nas declarações empresariais após os acidentes expressam o descaso com os trabalhadores terceirizados, como é observado na fala do representante da Comissão de Relações de Trabalho do SINDUSCON/ES: "a empresa não tem nada a ver com isso, a culpa é do trabalhador da terceirizada" (Depoimento de R., representante do SINDUSCON/ES, 2016), ou seja, o mais distante possível da empresa contratante. Assim, as empresas de fato transferem a responsabilidade aos entes interpostos, deixando de gerir de forma segura o processo de trabalho (COUTINHO, 2015).

Desse modo, como provocadora mais expressiva dos acidentes de trabalho e adoecimentos laborais, a terceirização causa danos irreparáveis aos direitos humanos da classe trabalhadora, tendo em vista que seu propósito é exatamente conferir efetividade ao "direito humano" por excelência do capital, que é garantir a máxima exploração do proletariado, conceito extraído de Marx, para quem a "exploração da força de trabalho é o primeiro 'direito humano' do capital" (1996, p. 405).

\section{CONSIDERAÇÕES FINAIS}

O resultado deste estudo permitiu concluir a existência de risco de morte por acidentes entre a força de trabalho terceirizada da construção civil no subsetor de edificações na Grande Vitória/ES. Tal conclusão corrobora o contexto geral de alargamento da vulnerabilidade social da força de trabalho promovida pela terceirização, visto que, na base piramidal das relações 
sociais de trabalho, os terceirizados são aqueles que não têm segurança, seja porque trabalham em péssimas condições, seja porque as empresas terceiras abrem e fecham com muita facilidade, dificultando qualquer garantia trabalhista (ANTUNES; DRUCK, 2014).

Do ponto de vista empresarial, a justificativa parece estar clara para que em uma nova norma não exista restrição alguma à terceirização de atividades, uma vez que essa modalidade de organização abre a possibilidade de potencializar a redução de custos, em especial o de trabalho. Do ponto de vista dos trabalhadores, a defesa de severa restrição a essa prática também parece estar clara.

Não se tem conhecimento de estudos que apontem benefícios concretos para os trabalhadores terceirizados (DRUCK; FRANCO, 2007). Ao contrário, os estudos realizados apontam para consequências danosas para os que trabalham nessas condições. Entre os problemas vividos por esses trabalhadores estão: diminuição de salários, redução de benefícios sociais, diminuição da qualificação da força de trabalho, jornadas de trabalho mais extensas, piora das condições de saúde e de segurança no ambiente laboral e, ainda, desorganização da representação sindical (COUTINHO, 2015).

Conclui-se finalmente que a terceirização na contratação da força de trabalho na construção civil de edificações na região da Grande Vitória/ES não contribui para a melhoria das condições laborais desses trabalhadores e se expressa na imposição de jornadas extenuantes, com alto índice de acidentes e doenças adquiridas no ambiente de trabalho. Essa realidade demonstra o real significado da terceirização para as condições laborais da força de trabalho do setor da construção civil.

\section{REFERÊNCIAS}

ALVES, Giovanni. Dimensões da precarização do trabalho: ensaios de Sociologia do Trabalho. Bauru: Canal 6, 2013.

ANTUNES, Ricardo; DRUCK, Graça. A epidemia da terceirização. In: ANTUNES, Ricardo (Org.). Riqueza e miséria do trabalho. São Paulo: Boitempo, 2014. v. III. p. 13-24.

AZEVEDO, Fernanda Caldas de. Consultoria empresarial de Serviço Social: expressões da precarização e da terceirização profissional. Serviço Social \& Sociedade, São Paulo: Cortez, n. 118, p. 318-338, abr./jun. 2014.

BRASIL. Ministério da Previdência Social. Anuário Estatístico de Acidente de Trabalho. Texto Explicativo. Seção IV: Acidentes de Trabalho. Brasília, DF, 2006.

BRASIL. Ministério da Previdência Social. Anuário Estatístico de Acidentes de Trabalho. Brasília, DF, 2013.

CHERCHIGLIA, Mariângela Leal. Terceirização do trabalho nos serviços de saúde: alguns aspectos conceituais, legais e pragmáticos. CADRHU, Rio de Janeiro: UFRJ, p. 1-15, 2004.

COUTINHO, Grijalbo Fernandes. Terceirização: máquina de moer gente trabalhadora. A inexorável relação entre a nova marchandage e a degradação laboral, as mortes e mutilações no trabalho. São Paulo: LTr , 2015.

CUNHA, Sebastião Ferreira da. Perfil do mercado de trabalho brasileiro e dos trabalhadores na construção civil. In: FILGUEIRAS, Vitor Araújo (Org.). Saúde e segurança do trabalho na construção civil brasileira. Aracaju: Ministério Público do Trabalho, 2015. p. 41-60.DAL ROSSO, Sadi. Mais trabalho! A intensificação do labor na sociedade contemporânea. São Paulo: Boitempo Editorial, 2008. 
DEJOURS, Christophe. A banalização da injustiça social. Rio de Janeiro: FGV, 2011.

DEJOURS, Christophe. Da psicopatologia à psicodinâmica do trabalho. Rio de Janeiro: Ed. da Fundação Oswaldo Cruz, 2004.

DEJOURS, Christophe. A loucura do trabalho: estudo de psicopatologia do trabalho. São Paulo: Cortez, 2003.

DIEESE. O processo de terceirização e seus efeitos sobre os trabalhadores no Brasil. Relatório Técnico. 2013. Disponível em: www.dieese.org.br. Acesso em: 13 mai. 2018.

DRUCK, Graça. Trabalho, precarização e resistências. Caderno CRH, Salvador, v. 24, n. esp. 1, p. 37-57, 2011.

DRUCK, Graça; FRANCO, Tânia. A perda da razão social do trabalho: terceirização e precarização. São Paulo: Boitempo, 2007.

FILGUEIRAS, Vitor Araújo. Terceirização e acidentes de trabalho na construção civil. In: FILGUEIRAS, Vitor Araújo (Org.). Saúde e segurança do trabalho na construção civil brasileira. Aracaju: Ministério Público do Trabalho, 2015. p. 61-86.

MARX, Karl. O capital: crítica da economia política. São Paulo: Abril Cultural, 1996.

MARCELINO, Paula. Trabalhadores terceirizados e luta sindical. Curitiba: Appris, 2013.

MÉSZÁROS, István. A crise estrutural do capital. São Paulo: Boitempo, 2011.

RODRIGUES, Patrícia Ferreira; ALVARO, Alex Leandro Teixeira; RONDINA, Regina. Sofrimento no trabalho na visão de Dejours. Revista Científica Eletrônica de Psicologia,ano IV, n.7, p. 1-8, nov. 2006.

SANTOS FILHO, Bertolino Bernardes dos. Trabalho e Saúde: a lombalgia em pedreiros de uma empresa da construção civil na Grande Vitória/ES. 2011. 81 f. Dissertação (Mestrado em Políticas Públicas e Desenvolvimento Local) - Programa de Pós-Graduação em Políticas Públicas e Desenvolvimento Local, Escola Superior de Ciências da Santa Casa de Misericórdia de Vitória, Vitória, 2011.

SEÇÃO PAU NA GATA. Jornal Operário da Construção, Vitória, n. 120, out. 2014. Disponível em: http://www.sintraconst-es.com.br/arquivos/jornais/jornal_120.pdf. Acesso em: 10 jun. 2018.

SEÇÃO PAU NA GATA. Jornal Operário da Construção, Vitória, n. 146, nov. 2016. Disponível em: http://www.sintraconst-es.com.br/arquivos/jornais/novembro_2016.pdf Acesso em: 10 jun. 2018.

SILVA, Maria Cristina V. de Cristo. Condições de Trabalho e Clima de Segurança dos Operários da Construção de Edificações. 2013b. 98 f. Dissertação (Mestrado em Psicologia) - Programa de Pós-Graduação em Psicologia, Universidade Federal de Minas Gerais, Belo Horizonte, 2013.

SOUZA, Renata Silva. A terceirização do trabalho no setor da construção civil na Grande Vitória/ES. 2017. 150 f. Dissertação (Mestrado em Política Social) - Programa de Pós-Graduação em Política Social, Universidade Federal do Espírito Santo, Vitória, 2017. 